Transactions of the American Fisheries Society, 2004, v.133, n.1, pp.121-131. ISSN: 0002-8487

DOI: $10.1577 / \mathrm{T} 03-020$

http://afs.allenpress.com/perlserv/?request=get-archive http://afs.allenpress.com/archive/1548-8659/133/1/pdf/i1548-8659-133-1-121.pdf (C) Copyright by the American Fisheries Society 2004 


\title{
Round Goby Predation on Smallmouth Bass Offspring in Nests during Simulated Catch-and-Release Angling
}

\author{
Geoffrey B. Steinhart,* Elizabeth A. Marschall, and Roy A. Stein \\ Aquatic Ecology Laboratory, Department of Evolution, Ecology, and Organismal Biology, \\ Ohio State University, 1314 Kinnear Road, Columbus, Ohio 43212-1156, USA
}

\begin{abstract}
Round goby Neogobius melanostomus first appeared in Lake Erie in 1993 and now occur in extremely high densities in some areas. As known nest predators, round goby currently pose a threat to nest-guarding smallmouth bass Micropterus dolomieu. We conducted manipulative experiments to evaluate the combined effects of round goby predation and catch-and-release angling during 1999-2001 in the Bass Islands, Lake Erie. We quantified how many smallmouth bass offspring were consumed by round goby when nest-guarding smallmouth bass males were present, removed, and recovering from angling-related stress. In $10 \mathrm{~h}$ of video observations, we only saw one instance of round goby consuming smallmouth bass offspring while the nest was guarded. Upon removal of nest-guarding smallmouth bass, round goby quickly entered unguarded nests (4.3 round goby/min for nests with unhatched embryos and 1.8 round goby/min for nests with hatched embryos). During experimental catch-and-release angling, round goby consumed an average of 2,000 unhatched embryos before the guardian male returned, but postreturn offspring losses were minimal while the male recovered from angling stress. For an average smallmouth bass nest in the Bass Islands, round goby could consume all offspring from an unguarded nest in about $15 \mathrm{~min}$. Round goby predation and smallmouth bass angling combined to reduce survival of smallmouth bass embryos, but we did not observe round goby consuming free-swimming larvae or juveniles. If the number of surviving smallmouth bass embryos drives adult population size, managers should consider angling regulations that reduce interference with nesting males, thus limiting the deleterious effects of round goby.
\end{abstract}

Predation is an important cause of mortality during the early life stages of many fishes (Houde 1987). In fishes, predator effects can be reduced by producing large numbers of offspring, by providing parental care, or by colonial nesting (Gross and MacMillan 1981; Sargent 1988). Because evolution of these reproductive strategies is tightly linked to the predator environment, survival from egg to adult may be compromised when the predation risk changes (Foote and Brown 1998). In light of the rapid rate of global homogenization of aquatic communities (Rahel 2000), introduced species are changing the predator environments in which fishes have evolved. In fact, the Great Lakes have been invaded by more than 145 species, many of which have had profound ecological and economic impacts on the ecosystem (Mills et al. 1993; Ricciardi and MacIsaac 2000).

Ample evidence exists that recently introduced predators affect recruitment of fish species that do not provide parental care. As early colonizers of postglaciation lakes, lake trout Salvelinus namaycush evolved when few predators existed, so lake trout are less successful in lakes with diverse fish

\footnotetext{
* Corresponding author: steinhart.3@osu.edu

Received February 3, 2003; accepted June 19, 2003
}

communities than in lakes with few species (Evans and Olver 1995). In the Great Lakes, a suite of exotic fishes has been blamed for lake trout restoration failures (Jones et al. 1995). For example, exotic rusty crayfish Orconectes rusticus consume significant numbers of lake trout eggs in certain substrates (Horns and Magnuson 1981). Furthermore, predation by exotic alewives Alosa pseudoharengus has caused poor and variable survival of young yellow perch Perca flavescens and bloaters Coregonus hoyi (Rice et al. 1987), while introduced rainbow smelt Osmerus mordax has compromised recruitment success of lake whitefish $C$. clupeaformis and lake herring $C$. artedi by preying on their larvae (Loftus and Hulsman 1986).

Predators also affect reproductive success of species that provide parental care (Sargent 1988). In nest-guarding fishes, potential predators are vigorously chased from nests at substantial metabolic cost to the nest guarder (Hinch and Collins 1991). As predator density increases, so does chase frequency and energetic cost of parental care, which ultimately could lead to offspring mortality or nest abandonment. Nest-guarding fathead minnow Pimephales promelas experienced higher egg survival in the absence of crayfish predators than with crayfish (Sargent 1988). Nest success of pumpkinseeds Lepomis gibbosus, a colonial nesting spe- 
cies with paternal care, was lower in a lake with abundant predatory cyprinids than in a lake with few cyprinids (Popiel et al. 1996).

A recent invader of the Great Lakes, the round goby Neogobius melanostomus, was accidentally introduced via ship ballast water and has quickly spread throughout Lake Erie. After first appearing in the St. Claire River in 1990, round goby were soon found in Lakes Michigan and Erie (1993), Lake Huron (1994), Lake Superior (1995), and Lake Ontario (1997; Charlebois et al. 1997). Round goby consume fish eggs and, although not dissimilar ecologically from native benthic fishes (e.g., sculpins Cottus spp. and darters Etheostoma spp.), could affect offspring survival for some fish species (Chotkowski and Marsden 1999). A benthic fish that reaches $15 \mathrm{~cm}$ and can spawn multiple clutches per year (Charlebois et al. 1997), round goby can reach extremely high densities $(>100$ fish $/ \mathrm{m}^{2}$ ) in Lake Erie. This has raised concerns about the species' potential to limit the reproductive success of indigenous fishes through predation on eggs, embryos, and larvae (Chotkowski and Marsden 1999; Janssen and Jude 2001).

Smallmouth bass Micropterus dolomieu nest on the lake bottom and, after courtship and spawning take place, the male cares for the developing offspring. Male parental care involves keeping the nest free from debris, circulating water to provide oxygen, and protecting offspring from predators (Hinch and Collins 1991). Although male smallmouth bass vigorously defend their offspring for up to 6 weeks (Ridgway 1988), some offspring are still eaten by predators (Clady 1975; Goff 1986; Knotek and Orth 1998), and predation causes many nest failures for nest-guarding smallmouth bass (Lukas and Orth 1995) as well as largemouth bass M. salmoides (Swenson 2002). Smallmouth bass offspring may be particularly vulnerable to round goby predation because smallmouth bass often nest in rocky habitats, where round goby are common (Charlebois et al. 1997). Presumably, nest defense in smallmouth bass has evolved to increase offspring survival in the face of predators, but high round goby densities may overwhelm smallmouth bass and, when combined with spring angling for adult smallmouth bass, could compromise juvenile smallmouth bass survival (Ridgway and Shuter 1997).

With removal of nest-guarding smallmouth bass by anglers, offspring are susceptible to predators (Kieffer et al. 1995; Philipp et al. 1997). Currently, angling for smallmouth bass during the spawning season is allowed in the Ohio and New York waters of Lake Erie. Even if anglers practice catch and release, nests are temporarily vulnerable to predation. In addition, recovery from angling requires several hours and may impair a male's ability to defend his nest (Kieffer et al. 1995; Cooke et al. 2000; Schreer et al. 2001). To assess the combined effects of round goby predation and angler removal of nest-guarding smallmouth bass on smallmouth bass offspring abundance, we conducted catchand-release angling experiments in which we measured (1) the number of offspring consumed from guarded and unguarded smallmouth bass nests, (2) the time required for angled smallmouth bass to return to nests, and (3) the number of offspring consumed during angling and after angled smallmouth bass had returned to their nests.

\section{Methods}

Study location.-Nesting smallmouth bass were located around the Bass Islands, a belt of islands and reefs situated in the western basin of Lake Erie $\left(41^{\circ} 40^{\prime} \mathrm{N}, 82^{\circ} 50^{\prime} \mathrm{W}\right)$. Smallmouth bass nests were typically found in water $2-4 \mathrm{~m}$ deep, with a cobble substrate over a cohesive clay base. Round goby were abundant in the habitats favored by spawning smallmouth bass (G. B. Steinhart, personal observation). Using scuba, we surveyed smallmouth bass nests during early May through June in Lake Erie, 1999-2001. Once located, nests used for predation experiments (1999 and 2000) were temporarily marked with a floating buoy while we observed and angled the nest-guarding male; these nests were not revisited. Because nests used in the 2000 and 2001 angling experiments were visited repeatedly, they were mapped and marked with a numbered tile. On each visit, nest status (occupied or abandoned) and offspring developmental stage (unhatched embryos, hatched embryos, larvae, or juveniles) were recorded. Successful nests were defined as nests that produced larvae (Ridgway et al. 1991).

Measurement of round goby entry and offspring consumption rates.-We used a remote underwater camera to record round goby predation while smallmouth bass guarded nests, and to assess the rates of predator entry and consumption when smallmouth bass were removed via simulated catch-and-release angling. During preliminary work, we occasionally observed round goby entering nests with free-swimming larvae and even chasing larvae; however, we never observed a round goby consuming a larva. Consequently, we focused our efforts on videotaping nests with unhatched embryos (10 nests) or hatched embryos 
(17 nests). When a nest was located, divers placed a video camera mounted on a $0.5-\mathrm{m}$ tripod within $0.5 \mathrm{~m}$ of the nest. Divers returned to the boat, waited $10 \mathrm{~min}$, and then began recording data on a combination TV/VCR connected to the video camera. We recorded nest-guarding behavior of smallmouth bass for $15 \mathrm{~min}$ before divers reentered the water and angled the male smallmouth bass from the nest with a rod and reel and a singlehook plastic jig. Divers remained suspended above and to the side of the nest while being careful not to disturb the substrate, and extended the rod to place the jig on the substrate within in the nest. Once the smallmouth bass was hooked, the diver passed the rod to a person in the support boat, who quickly reeled in the guarding male. Fish were weighed $( \pm 25 \mathrm{~g})$ and measured $( \pm 1 \mathrm{~mm}$ total length [TL]) before release (mean angling plus processing time $\pm \mathrm{SE}=84 \pm 8 \mathrm{~s}$ ). Although the presence of the diver may have influenced smallmouth bass and round goby behavior, the divers were present only during camera installation and angling, and during nest guarding, if applicable (see below).

We estimated the number of offspring consumed during simulated catch-and-release angling by measuring the entry and feeding rates of round goby in unguarded smallmouth bass nests from videotaped observations. Round goby behavior (e.g., entering or exiting a nest, consuming an embryo) from the videotapes was recorded with Beast software, a program for real-time recording and analysis of behavioral data. We summed all round goby entries and exits at 3-s intervals, combined with the number of round goby from the previous 3 -s interval, to estimate the number of round goby in each nest. In addition, we estimated the rate of offspring consumption by 78 individual round goby of various sizes (mean $=70 \mathrm{~mm}$ TL, range 42-136 mm) from videotapes. Total length was estimated by measuring round goby on the television screen and correcting based on an object of known size (i.e., a ruler or a tile) that was also present on the screen. We assumed an offspring was consumed when a round goby tilted toward the substrate and flared its gills to suck in an offspring. Observations of round goby consumption lasted for the entire time the focal round goby was in the nest, and we observed individuals at various times after a nest was left unguarded. Total number of offspring consumed from an unguarded nest through time (s) was calculated as: number of offspring consumed through time $T$

$$
\begin{aligned}
=\sum_{t=0}^{T}[\text { number of round goby }(t) \\
\left.\times \frac{\text { number of offspring consumed }}{\text { round goby } \times 3 \mathrm{~s}}\right],
\end{aligned}
$$

where $t=0,3,6, \ldots, T$. We measured round goby entry and consumption rates in nests containing unhatched embryos and in nests with hatched embryos. For statistical analyses, we included only those nests left unguarded for $5 \mathrm{~min}$ or longer (6 nests with unhatched embryos and 10 with hatched embryos). We used analysis of covariance (ANCOVA) to test whether the mean number or entry rate of round goby in unguarded nests differed between nests with offspring at different developmental stages. The model used offspring stage (unhatched or hatched embryos) as a class variable and the time since the guarding male was removed (0-300 $\mathrm{s}$ in 3-s intervals) as the covariate. We specifically were interested in determining the interaction between offspring stage and time since removal, to see if there was a significant difference $(\alpha=0.05)$ in the rate of round goby entry.

Effect of holding time on smallmouth bass return time.-To quantify the time smallmouth bass required to return to their nests after release, and to determine if holding time affected return time, we held angled smallmouth bass for different lengths of time before release. In 1999, fish were either immediately released (18 fish) or held for $6 \mathrm{~min}$ prior to release (12 fish). In 2000, treatments were immediate release or 2, 6, or 12-min holding periods before release ( $\mathrm{six}$ fish for each treatment), with treatments systematically assigned. Holding time was in addition to angling and handling times (84 $\pm 8 \mathrm{~s}$, as described earlier). Fish were held in a cooler filled with lake water before release into the lake. Return time was recorded when the guarding male appeared on the TV/VCR at the nest and resumed parental care. We used an analysis of variance (ANOVA) model to test if treatment (holding time) or male TL (mean $=364 \mathrm{~mm}$, range = 270-468 mm; two fish were not measured, leaving a sample size of 52) affected return time.

Changes in nest size and embryo density during and after catch-and-release angling.-To more directly estimate the effects of round goby predation, we measured smallmouth bass nest area before and after catch-and-release angling of the nestguarding male. Because angling causes physiolog- 
ical stress that can last for several hours, parental care may be compromised during this postangling recovery period, so we designed treatments to separate offspring losses during angling from losses during postangling recovery. In 2000 and 2001, smallmouth bass nests were assigned to one of three treatments: (1) control (no angling), (2) angling without predation, where nests were guarded by a scuba diver until the male returned (i.e., only postangling offspring losses), and (3) angling with predation, where nests were exposed to predators (i.e., offspring losses during angling and postangling). Angling methods were as previously described, except that all smallmouth bass were jaw tagged before release (mean angling plus processing time $\pm \mathrm{SE}=146 \pm 11 \mathrm{~s}$ ). Tagging ensured proper identification because smallmouth bass sometimes used nests abandoned by other smallmouth bass (G. B. Steinhart, personal observation).

For each nest, we traced the perimeter occupied by broods before angling and on the next visit, an average of $4 \mathrm{~d}$ later (range 1-8 d). Nest tracings (34 nests) were made on a clear acrylic sheet, and nest area was quantified by use of a digitizing tablet with SigmaScan software. We used ANCOVA to test whether change in brood area was affected by treatment. The number of days between tracings served as a covariate. To determine if brood losses occurred during angling or during postangling recovery of the nest-guarding male, we used leastsignificant-difference tests with the Tukey-Kramer correction for multiple comparisons to compare change in brood area between control and anglingwithout-predation or angling-with-predation treatments. We also compared brood area between the two angling treatments (with predation and without predation). In addition, we estimated embryo density before and after angling with photographs of nests containing unhatched embryos (46 nests before angling and 21 nests after angling). Nests with hatched offspring were not used because the offspring blended into the background and wiggled into interstitial spaces. Unhatched embryo densities were estimated from digitized photographs enhanced with Optimas image analysis software; densities were determined by averaging the number of unhatched embryos counted in six, randomly selected, $4-\mathrm{cm}^{2}$ areas within the brood $(\sim 5 \%$ of brood area). A similar method, which incorporated scuba divers' counts of unhatched embryos, produced results comparable to counts of all unhatched embryos in the nest or in nest photographs (Raffetto et al. 1990). We used ANOVA to test whether embryo density differed among angling treatments. We also tested for angling treatment effect on initial (pre-angling) density to ensure that there had been no bias in nest selection for treatment assignment.

\section{Results}

\section{Round Goby Entry Rate into Smallmouth Bass Nests}

Round goby were the primary predator on smallmouth bass offspring ( $>99 \%$ of predators observed). On two occasions, logperch Percina caprodes entered unguarded nests; in one case, a rock bass Ambloplites rupestris ate unhatched embryos from an unguarded nest (nest not included in analyses). In $10 \mathrm{~h}$ of video observations, only once did a round goby eat offspring from a guarded smallmouth bass nest. For unguarded nests, the average time to first entry by a round goby was $78 \mathrm{~s}$ (range $=2-288 \mathrm{~s}$ ), with many other round goby following. During the first $5 \mathrm{~min}$ after bass removal, round goby entered nests with unhatched embryos more rapidly ( 4.3 round goby/min) than they entered nests with hatched embryos (1.8 round goby/ min; offspring stage $\times$ time since removal: $F_{1,198}$ $=702.7, P<0.0001$; Figure 1$)$. As a result, within 5 min after the guarding smallmouth bass was removed, nests with unhatched embryos contained an average of 20 round goby (range $=9-34$; Figure 1) and nests with hatched embryos had 9 round goby (range $=0-18$ ). From 5 to $15 \mathrm{~min}$ after guardian male removal, the mean density of round goby (17 per nest with unhatched embryos, and 12 per nest with hatched embryos) was relatively stable at over 200 round goby $/ \mathrm{m}^{2}$.

\section{Round Goby Consumption Rate}

After entering nests containing unhatched or hatched embryos, each round goby ate an average of one embryo every $3.5 \pm 2.2 \mathrm{~s}$ (mean $\pm \mathrm{SD}$ ) for the duration of its visit. During an average visit $(69.2 \pm 59.1 \mathrm{~s})$, a round goby consumed $18.0 \pm$ 21.6 offspring. Based on the average consumption rate and the average number of round goby in an unguarded nest, we estimated that round goby consumed approximately 1,000 unhatched embryos or 400 hatched embryos during the average time a guardian male was absent following catch-andrelease angling ( $\sim 5 \mathrm{~min}$; Figure 1; see "effect of holding time" below). Offspring consumption rate by all round goby in the nest was higher in nests with unhatched embryos (2.8 unhatched embryos/ s) than in nests with hatched embryos (1.0 hatched embryos/s) during the first 5 min after the guarding 


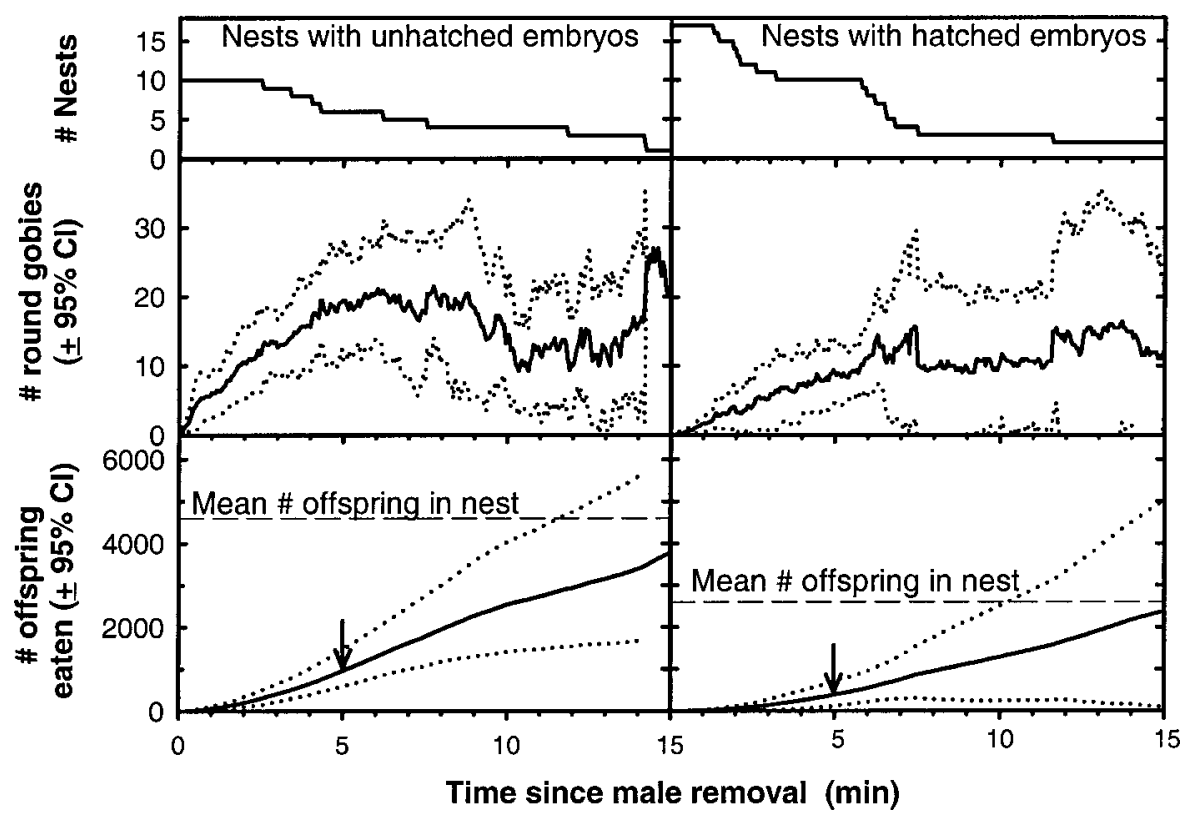

FIGURE 1.-Number of round goby in nests and number of smallmouth bass offspring consumed since male smallmouth bass removal from nests containing unhatched or hatched embryos in the Bass Islands, Lake Erie, during 1999 and 2000. The top panel shows the number of nests observed. The middle panel gives the mean and $95 \%$ confidence intervals of the number of round goby in a nest. The bottom panel illustrates the mean and $95 \%$ confidence intervals of the number of offspring consumed by round goby.

male was removed. An estimated 3,800 unhatched embryos or 2,400 hatched embryos were consumed within 15 min while male smallmouth bass were held away from their nests (Figure 1). Given this rate of consumption, an average smallmouth

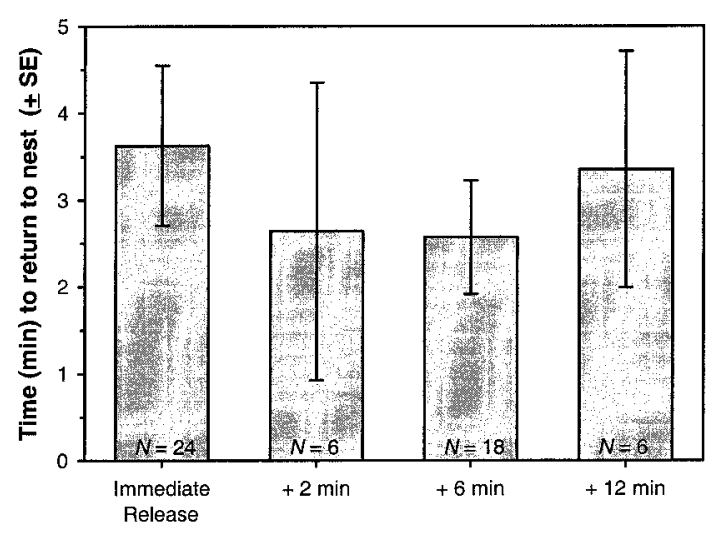

Time held after capture

FiguRE 2.-Average time taken by nest-guarding smallmouth bass to return to their nests after catch-andrelease angling during May-June, 1999-2000, in the Bass Islands, Lake Erie. Time held after capture refers to how long a smallmouth bass was held in a cooler in lake water before release. bass brood in Lake Erie (mean $\pm \mathrm{SE}=4,600 \pm$ 360 unhatched embryos) would be entirely consumed by round goby in approximately $17 \mathrm{~min}$, assuming that the consumption rate remains constant.

\section{Effect of Holding Time on Smallmouth Bass Return Time}

Male smallmouth bass exhibited highly variable return times to their nests (Figure 2). Return time was unaffected by time held after capture $\left(F_{3,47}=\right.$ $0.3, P=0.82)$ or by TL $\left(F_{1,47}=1.5, P=0.22\right)$. With no consistent pattern for return times, we generated a probability distribution of the return times for angled smallmouth bass based on all return times measured during 1999-2000 (84 males; mean $\pm \mathrm{SE}=188 \pm 31 \mathrm{~s}$ ). To these return times, we added 2 min for angling and handling to allow calculation of the total time a male might be absent from his nest. Our mean angling plus handling time was $1.4 \mathrm{~min}$, but typical anglers may take longer to release a fish if they use multi-hook lures (longer time to unhook fish) or if they weigh, measure, and photograph the catch. We converted the distribution of absence times to the predicted number of unhatched or hatched embryos consumed (Figure 3). A 0.5 probability exists that at least 1,100 


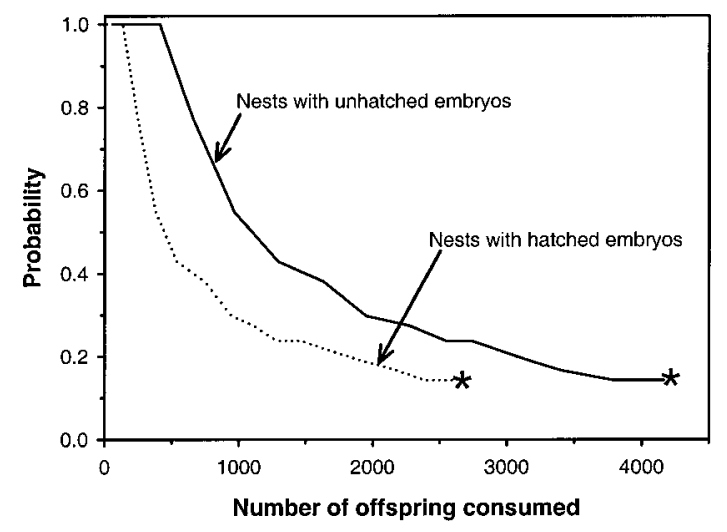

FIGURE 3.-Probability of the average number of offspring consumed by round goby from smallmouth bass nests during a typical catch-and-release angling event in the Bass Islands, Lake Erie. Probabilities were based on the frequency distribution of return times for 84 male smallmouth bass, including a 2-min angling and handling time before release, during May-June, 1999-2001. Asterisks indicate the minimum number of offspring consumed from nests to which the male smallmouth bass did not return during our postrelease observation period (15 $\mathrm{min})$. unhatched embryos or 500 hatched embryos would be consumed during catch-and-release angling, and a 0.25 probability exists that at least 2,400 unhatched embryos or 1,200 hatched embryos would be consumed. The expected, or average, number of offspring consumed by round goby was 1,600 unhatched embryos or 800 hatched embryos during a single catch-and-release angling of a nestguarding smallmouth bass. Thus, about $35 \%$ of the offspring in an average Lake Erie smallmouth bass nest were lost during a typical instance of catchand-release angling.

\section{Changes in Nest Size and Embryo Density during and after Catch-and-Release Angling}

Angling treatment affected the change in nest area occupied by unhatched embryos $\left(F_{2,30}=4.41\right.$, $P=0.021)$, but the number of days $(1-4 \mathrm{~d})$ between tracings did not $\left(F_{1,30}=2.46, P=0.13\right)$; consequently, we assumed that offspring losses occurred during or immediately after catch-andrelease angling, not during the days between tracings (Figure 4). Nests exposed to predation during angling lost an average of $222 \mathrm{~cm}^{2}$, or $34 \%$, of the area occupied by unhatched embryos, which was greater than the average loss of $14 \mathrm{~cm}^{2}$ from nests guarded by scuba divers during angling (least sig-

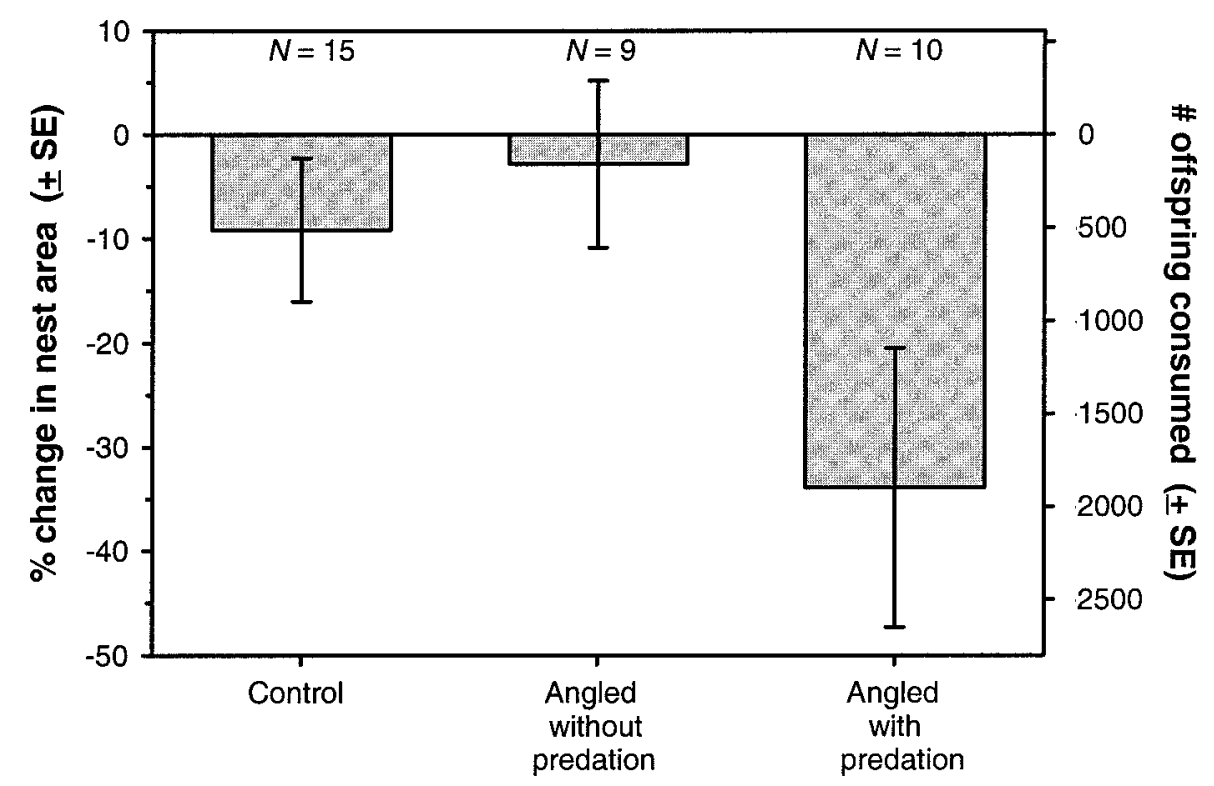

\section{Treatment}

FIGURE 4.-Change in nest area, after an average of $4 \mathrm{~d}$ between sampling, for smallmouth bass nests assigned to experimental treatments in Lake Erie, 2000-2001. Treatments were defined as follows: control (no angling), angling without predation (angling with nests guarded by a scuba diver), and angling with predation (angling with nests exposed to predators). 
nificant difference, $t=2.81, P=0.023)$. Nests not subjected to angling (control nests) lost an average of $70 \mathrm{~cm}^{2}$, which was not significantly different than losses from nests guarded by divers during angling (least significant difference, $t=$ $0.82, P=0.69$ ) or unguarded, angled nests (least significant difference, $t=2.31, P=0.069$ ). Embryos were typically arranged in a single layer, and embryo density (measured from photographs) did not differ between treatments before angling $\left(F_{2,44}=0.25, P=0.78\right)$ or after angling $\left(F_{2,19}=\right.$ $0.96, P=0.40)$. Therefore, we calculated mean unhatched embryo density for all nests (mean \pm $\mathrm{SE}=8.6 \pm 0.4 \mathrm{eggs} / \mathrm{cm}$ ) and multiplied it by change in nest area for each treatment. From these estimates, control nests lost a mean of 600 unhatched embryos, and nests guarded by divers during angling lost a mean of 200 unhatched embryos (Figure 4), representing 4-13\% of the embryos in an average smallmouth bass nest in Lake Erie. When nests were left unguarded during catch-andrelease angling, however, they lost an average of 2,000 unhatched embryos, or $43 \%$ of the unhatched embryos in an average nest.

\section{Timing of Smallmouth Bass Spawning}

Smallmouth bass began spawning in early May and continued guarding broods until early July in 2000-2001 (Figure 5). Nests where the guarding male was not angled and which were active in May ultimately failed, primarily due to storms (G. Steinhart, unpublished data). Nests that were ultimately successful were those occupied in June and July. Over the 3 years of this study, successful nests contained nonmobile embryos primarily during a 2-week period from 6 to 20 June.

\section{Discussion}

Despite the high density of round goby in Lake Erie, nest-guarding smallmouth bass males were able to defend their offspring from potential predators, except when removed from nests by angling. During our experiments, round goby consumed $20-50 \%$ of the offspring in a smallmouth bass nest during catch-and-release angling. Survival from egg deposition to maturity is often very low for smallmouth bass (Clady 1975), and only a few nests may produce the majority of juveniles surviving until fall (Gross and Kapuscinski 1997). Even a small increase in episodic predation can further reduce recruitment to adulthood (Houde 1989) and, when the nest predator is a recent and hyperabundant invader, mortality via nest predation may be significant.

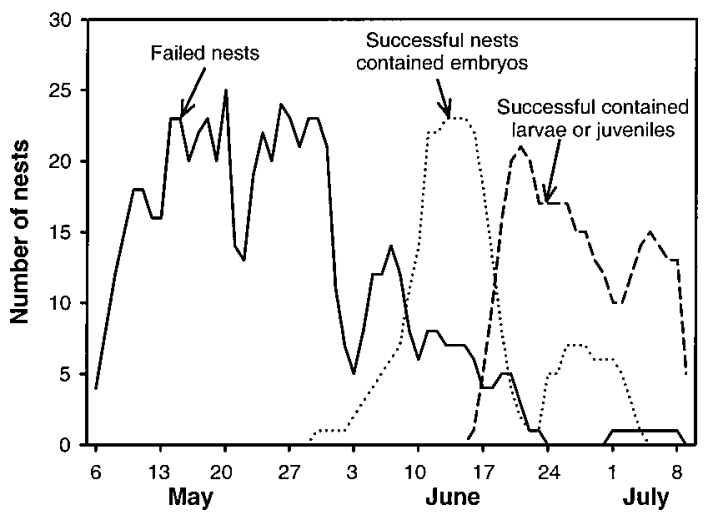

FIGURE 5.-Number of guarded smallmouth bass nests $(N=141)$ present each day during 6 May to 9 July 2000-2001 at our sample sites in the Bass Islands, Lake Erie. Lines reveal the number of guarded nests on each day for nests that ultimately failed (i.e., never produced free-swimming larvae) or that were ultimately successful. Data for successful nests were split into periods when nests contained nonmobile embryos (i.e., vulnerable to round goby predation) or less-vulnerable, freeswimming larvae or juveniles. We did not remove guarding males from the nests depicted in the graph, but they were susceptible to local anglers.

We estimated that round goby could consume an entire smallmouth bass brood in little more than 15 min, a result of the high densities and gregarious nature of round goby. Our estimates, however, assumed a constant consumption rate (one offspring every $3.5 \mathrm{~s}$ ). Often, predation rate is modeled as a declining function due to predator satiation and because reduced prey abundance increases search times. Our estimate of round goby consumption was calculated based on entire round goby visits, from the time an individual round goby entered the nest to the moment it left. Therefore, time spent searching for prey, interacting with other round goby, and changes in appetite owing to satiation were accounted for in our estimate of consumption rate. In our observations, round goby were constantly entering and exiting nests, thus there were new (i.e., not satiated) round goby entering a nest at various times. In this situation, long search times are unlikely, as smallmouth bass embryos are nonmobile and confined within small nests (mean brood area $\pm \mathrm{SD}=0.05$ $\pm 0.02 \mathrm{~m}^{2}$ ). Even if we have overestimated the round goby consumption rate, the nonmobile smallmouth bass offspring, confined to a small area and exposed to high predator densities, are nevertheless extremely vulnerable to predation.

In fact, our data could underestimate the actual 
number of offspring consumed because we quickly reeled the smallmouth bass to the boat and released it near its nest after a short holding time. In practice, fish are occasionally played to exhaustion, which increases return time (up to four times as long; Kieffer et al. 1995). In addition, fish are often held out of water for longer periods than were used in our experiments, especially when hooks are deeply imbedded or when the catch elicits measurements and photographs. Holding a smallmouth bass out of the water for just $1 \mathrm{~min}$ increases return times two- to threefold (Philipp et al. 1997). Further, as angling or handling times increase, the angler's boat may move farther from the nest, which also increases return time (Philipp et al. 1997). In extreme cases (e.g., fishing tournaments), smallmouth bass may be held for several hours or transported several kilometers before release, almost assuring total nest destruction. In addition, angled smallmouth bass experience significant physiological stress that requires several hours of recovery, especially when they are played to near exhaustion (Schreer et al. 2001). In fact, locomotory behavior of nest-guarding male largemouth bass was impaired for more than $24 \mathrm{~h}$ after angling (Cooke et al. 2000). During this recovery period, parental care could be compromised. However, because neither smallmouth bass nest area nor egg number declined for nests guarded by scuba divers during angling (i.e., angling-withoutpredation treatment), nest predation was not apparent during postangling recovery of the guarding male.

Even though we quantified the impact of round goby on individual smallmouth bass nests, we did not directly measure their effect on the total number of juveniles that survived to fall or beyond. In fishes, recruitment of larvae to juveniles, and of juveniles to adults, is highly variable and can be related to both environmental factors and predation (Houde 1987, 1989). Frequently, mortality during early life stages, including egg predation by benthic predators, can determine recruitment success (Rice et al. 1987; Bouwes and Luecke 1997; Foote and Brown 1998). Although there are few data on smallmouth bass, the number of offspring produced from largemouth bass nests may drive adult abundance (Summerfelt 1975; Fuhr et al. 2002). Thus, the combined effects of round goby and anglers, which reduce the number of offspring in a brood, may ultimately influence cohort success.

Clearly, there are many factors that can affect smallmouth bass recruitment success, and the question of what controls recruitment success is still under debate. What is evident, however, is that smallmouth bass were adapted to a particular environment in Lake Erie and, since the introduction of the round goby, predation risk has changed there. Although we observed many nest failures associated with strong winds, storms have always affected Lake Erie, whereas round goby have arrived only recently. Furthermore, in Ohio waters of Lake Erie, angling has long been allowed during smallmouth spawning, but a 10 -fold increase in angler effort targeting smallmouth bass since 1985 (Lichtkoppler and Hushak 2001), coupled with the invasion by round goby, could increase mortality of smallmouth bass (Philipp et al. 1997; Ridgway and Shuter 1997).

Given that smallmouth bass repeatedly spawn in the same location and aggressively defend their nests, anglers easily target them during the parental-care period (Ridgway 1988; Ridgway et al. 1991). Male vulnerability, coupled with nest predation by introduced species, brings into question the practice of spring angling for smallmouth bass. At a minimum, anglers should be encouraged to shorten playing and handling times of nestguarding males (Philipp et al. 1997; Cooke et al. 2000); however, additional protections may be needed. Managers use a variety of fishing regulations, including closed seasons, length limits, creel limits, and sanctuaries, to protect species vulnerable to overharvest (Fox 1975). Closed seasons often are used to protect spawning fish, but must coincide with critical spawning periods (Kubacki et al. 2002). In Lake Erie, smallmouth bass nested during early May through early July, but successful nests did not occur until June (Figure 5). Further, round goby consumed few free-swimming offspring; consequently, angling restrictions will be most beneficial when successful nests contain embryos. Unfortunately, compliance with closed seasons is often poor (Kubacki et al. 2002). Illegal or incidental catch and release often occurs (Sztramko 1985; Philipp et al. 1997), thereby making data comparisons before and after regulation changes difficult. Indeed, an estimated $63 \%$ of anglers in four systems in Ontario fished for smallmouth bass and/or largemouth bass during the closed season (Philipp et al. 1997). Even if observed, results suggest that closed seasons do not necessarily improve smallmouth bass recruitment. In eastern Lake Erie, moving from a closed to open season during smallmouth bass nesting in New York waters produced no change in smallmouth bass relative abundance (Einhouse et al. 2002). 
An alternative tool, more common in marine systems than in freshwater systems, is the establishment of sanctuaries and no-take reserves (Murray et al. 1999). Marine reserves can prevent collapse and enhance speedy recovery of overfished stocks; indeed, fish biomass rapidly increases after reserve establishment (Roberts et al. 2001). The creation of a sanctuary in Long Point Bay, Lake Erie, resulted in increased smallmouth bass catch per unit effort, a consequence of either lowered preseason harvest or greater recruitment stemming from reduced interference with nesting males (Sztramko 1985). Voluntary sanctuaries observed during smallmouth bass spawning in Ontario led to reduced angling pressure and higher nest success inside the sanctuaries compared to outside (Suski et al. 2002). In addition, when a northern Wisconsin lake was closed to fishing year-round, largemouth bass nest success increased and nest predation decreased; however, these effects may have resulted from a combination of reduced angling during spawning and changes in the size structure of the population (Swenson 2002).

In Lake Erie, the effects of angling and round goby predation during the spawning season on smallmouth bass cohort survival are unknown, but must be recognized as a new source of mortality. As such, round goby predation may compromise recruitment success. In the past, substantial proof of damage has been required before limiting a fishery, but with the current rate of species introductions (Rahel 2000; Ricciardi and MacIsaac 2000), managers should allow for some uncertainty when making decisions (Murray et al. 1999). At a minimum, future efforts should include assessing exploitation rates of nesting smallmouth bass, and encouraging anglers to promptly and carefully release their catch.

\section{Acknowledgments}

The authors would like to thank the Ohio Department of Natural Resources, Division of Wildlife, for their assistance with this project. In particular, Roger Knight contributed to the design of this study and the review of this manuscript. In addition, we would like to thank all the personnel at the Ohio State University Aquatic Ecology Laboratory and Stone Laboratory for their assistance. Special thanks to Nancy Leonard, who braved the cold and stormy waters of Lake Erie to help collect these data, and to the many researchers who helped G. B. Steinhart in the field. Thanks to John Janssen and two anonymous reviewers for comments that improved this manuscript. This research was fund- ed by Federal Aid in Sport Fish Restoration Project F-69-P, administered jointly by the U.S. Fish and Wildlife Service and the Ohio Department of Natural Resources, Division of Wildlife, and the Department of Evolution, Ecology, and Organismal Biology at Ohio State University.

\section{References}

Bouwes, N., and C. Luecke. 1997. The fate of Bonneville cisco eggs in Bear Lake: evaluating mechanisms for egg loss. Transactions of the American Fisheries Society 126:240-247.

Charlebois, P. M., E. J. Marsden, R. G. Goettel, R. K. Wolfe, D. J. Jude, and S. Rudnika. 1997. The round goby, Neogobius melanostomus (Pallas), a review of European and North American literature. IllinoisIndiana Sea Grant Program and Illinois Natural History Survey, Special Publication 20, Champaign, Illinois.

Chotkowski, M. A., and E. J. Marsden. 1999. Round goby and mottled sculpin predation on lake trout eggs and fry: field predictions from laboratory experiments. Journal of Great Lakes Research 25:2635 .

Clady, M. D. 1975. Early survival and recruitment of smallmouth bass in northern Michigan. Journal of Wildlife Management 39:194-200.

Cooke, S. J., D. P. Philipp, J. F. Schreer, and R. S. McKinley. 2000. Locomotory impairment of nesting male largemouth bass following catch-and-release angling. North American Journal of Fisheries Management 20:968-977.

Einhouse, D. W., W. J. Culligan, and J. Prey. 2002. Changes in the smallmouth bass fishery in New York's portion of Lake Erie with initiation of a spring black bass season. Pages 603-614 in D. P. Philipp, and M. S. Ridgway, editors. Black bass: ecology, conservation, and management. American Fisheries Society, Symposium 31, Bethesda, Maryland.

Evans, D. O., and C. H. Olver. 1995. Introduction of lake trout (Salvelinus namaycush) to inland lakes of Ontario, Canada: factors contributing to successful introductions. Journal of Great Lakes Research 21: 30-53.

Foote, C. J., and G. S. Brown. 1998. Ecological relationship between freshwater sculpins (genus Cottus) and beach-spawning sockeye salmon (Oncorhynchus nerka) in Iliamna Lake, Alaska. Canadian Journal of Fisheries and Aquatic Sciences 55:15241533 .

Fox, A. C. 1975. Effects of traditional harvest regulations on bass populations and fishing. Pages 392398 in R. H. Stroud, and H. Clepper, editors. Black bass biology and management. Sport Fishing Institute, Washington, D. C.

Fuhr, M. A., D. H. Wahl, and D. P. Philipp. 2002. Fall abundance of age-0 largemouth is more important than size in determining age-1 year-class strength in Illinois. Pages 91-100 in D. P. Philipp, and M. S. Ridgway, editors. Black bass: ecology, conser- 
vation, and management. American Fisheries Society, Symposium 31, Bethesda, Maryland.

Goff, G. P. 1986. Reproductive success of male smallmouth bass in Long Point Bay, Lake Erie. Transactions of the American Fisheries Society 115:415423.

Gross, M. L., and A. R. Kapuscinski. 1997. Reproductive success of smallmouth bass estimated and evaluated from family-specific DNA fingerprints. Ecology 78:1424-1430.

Gross, M. R., and A. M. MacMillan. 1981. Predation and the evolution of colonial nesting in bluegill sunfish (Lepomis macrochirus). Behavioural Ecology and Sociobiology 8:163-174.

Hinch, S. G., and N. C. Collins. 1991. Importance of diurnal and nocturnal nest defense in the energy budget of male smallmouth bass: insights from direct video observation. Transactions of the American Fisheries Society 120:657-663.

Horns, W. H., and J. J. Magnuson. 1981. Crayfish predation on lake trout eggs in Trout Lake, Wisconsin. Rapports et Procès-Verbaux des Réunions du Conseil International pour l'Exploration de la Mer 178: 299-303.

Houde, E. D. 1987. Fish early life dynamics and recruitment variability. Pages $17-29$ in R. D. Hoyt, editor. 10th Annual Larval Fish Conference, American Fisheries Society Symposium 2, Bethesda, Maryland.

Houde, E. D. 1989. Subtleties and episodes in the early life of fishes. Journal of Fish Biology 35:29-38.

Janssen, J., and D. J. Jude. 2001. Recruitment failure of mottled sculpin Cottus bairdi in Calumet Harbor, southern Lake Michigan, induced by the newly introduced round goby Neogobius melanostomus. Journal of Great Lakes Research 27:319-328.

Jones, M. L., G. W. Eck, D. O. Evans, M. C. Fabrizio, M. H. Hoff, P. L. Hudson, J. Janssen, D. J. Jude, R. O'Gorman, and J. F. Savino. 1995. Limitations to lake trout (Salvelinus namaycush) rehabilitation in the Great Lakes imposed by biotic interactions occurring at early life stages. Journal of Great Lakes Research 21 (Supplement 1):505-517.

Kieffer, J. D., M. R. Kubacki, F. J. S. Phelan, D. P. Phillip, and B. L. Tufts. 1995. Effects of catch-andrelease angling on nesting male smallmouth bass. Transactions of the American Fisheries Society 124: 70-76.

Knotek, W. L., and D. J. Orth. 1998. Survival for specific life intervals of smallmouth bass, Micropterus dolomieu, during parental care. Environmental Biology of Fishes 51:285-296.

Kubacki, M. F., F. J. S. Phelan, J. E. Claussen, and D. P. Philipp. 2002. How well does a closed season protect spawning bass in Ontario? Pages 379-386 in D. P. Philipp, and M. S. Ridgway, editors. Black bass: ecology, conservation, and management. American Fisheries Society, Symposium 31, Bethesda, Maryland.

Lichtkoppler, F. R., and L. Hushak. 2001. Ohio's 1998 Lake Erie charter fishing industry. Fisheries 26(1): 15-23.
Loftus, D. H., and P. F. Hulsman. 1986. Predation on larval lake whitefish (Coregonus clupeaformis) and lake herring (C. artedii) by adult rainbow smelt (Osmerus mordax). Canadian Journal of Fisheries and Aquatic Sciences 43:812-818.

Lukas, J. A., and D. J. Orth. 1995. Factors affecting nesting success of smallmouth bass in a regulated Virginia stream. Transactions of the American Fisheries Society 124:726-735.

Mills, E. L., J. H. Leach, J. T. Carlton, and C. L. Secor. 1993. Exotic species in the Great Lakes: a history of biotic crisis and anthropogenic introductions. Journal of Great Lakes Research 19:1-54.

Murray, S. N., R. F. Ambrose, J. A. Bohnsack, L. W. Botsford, M. H. Carr, G. E. Davis, P. K. Dayton, D. Gotshell, D. R. Gunderson, M. A. Hixon, J. Lubchenco, M. Mangel, A. MacCall, D. A. McArdle, J. C. Ogden, J. Roughgarden, R. M. Starr, M. J. Tegner, and M. M. Yoklavich. 1999. No-take reserve networks: sustaining fishery population and marine ecosystems. Fisheries 24(12):11-25.

Philipp, D. P., C. A. Toline, M. F. Kubacki, and D. B. F. Philipp. 1997. The impact of catch-and-release angling on the reproductive success of smallmouth bass and largemouth bass. North American Journal of Fisheries Management 17:557-567.

Popiel, S. A., A. Perez-Fuentetaja, D. J. McQueen, and N. C. Collins. 1996. Determinants of nesting success in the pumpkinseed (Lepomis gibbosus): a comparison of two populations under different risks of predation. Copeia 3:649-656.

Raffetto, N., S., J. R. Baylis, and S. L. Serns. 1990. Complete estimates of reproductive success in a closed population of smallmouth bass (Micropterus dolomieui). Ecology 71:1523-1535.

Rahel, F. 2000. Homogenization of fish faunas across the United States. Science 288:854-856.

Ricciardi, A., and H. J. MacIsaac. 2000. Recent mass invasion of the North American Great Lakes by Ponto-Caspian species. Trends in Ecology and Evolution 15:62-65.

Rice, J. A., L. B. Crowder, and F. P. Binkowski. 1987. Evaluating potential sources of mortality for larval bloater (Coregonus hoyi): starvation and vulnerability to predation. Canadian Journal of Fisheries and Aquatic Sciences 44:467-472.

Ridgway, M. S. 1988. Developmental stage of offspring and brood defense in smallmouth bass (Micropterus dolomieu). Canadian Journal of Zoology 66:17221728.

Ridgway, M. S., J. A. MacLean, and J. C. MacLeod. 1991. Nest-site fidelity in a centrarchid fish, the smallmouth bass (Micropterus dolomieu). Canadian Journal of Zoology 69:3103-3105.

Ridgway, M. S., and B. J. Shuter. 1997. Predicting the effects of angling for nesting smallmouth bass on production of age-0 fish with an individual-based model. North American Journal of Fisheries Management 17:568-580.

Roberts, C. M., J. A. Bohnsack, F. Gell, J. P. Hawkins, and R. Goodridge. 2001. Effects of marine reserves on adjacent fisheries. Science 294:1920-1923. 
Sargent, R. C. 1988. Parental care and egg survival both increase with clutch size in the fathead minnow, Pimephales promelas. Behavioral Ecology and Sociobiology 23:33-37.

Schreer, J. F., S. J. Cooke, and R. S. McKinley. 2001. Cardiac response to variable forced exercise at different temperatures: an angling simulation for smallmouth bass. Transactions of the American Fisheries Society 130:783-795.

Summerfelt, R. C. 1975. Relationship between weather and year-class strength of largemouth bass. Pages 166-174 in R. H. Stroud, and H. Clepper, editors. Black bass biology and management. Sport Fishing Institute, Washington, D. C.

Suski, C. D., F. J. S. Phelan, M. F. Kubacki, and D. P.
Philipp. 2002. The use of sanctuaries for protecting nesting black bass from angling. Pages $371-378$ in D. P. Philipp, and M. S. Ridgway, editors. Black bass: ecology, conservation, and management. American Fisheries Society, Symposium 31, Bethesda, Maryland.

Swenson, W. A. 2002. Demographic changes in a largemouth bass population following closure of the fishery. Pages 627-638 in D. P. Philipp, and M. S. Ridgway, editors. Black bass: ecology, conservation, and management. American Fisheries Society, Symposium 31, Bethesda, Maryland.

Sztramko, L. K. 1985. Effects of a sanctuary on the smallmouth bass fishery of Long Point Bay, Lake Erie. North American Journal of Fisheries Management 5:233-241. 